\title{
Research on Modern Agriculture Evaluation Index System of Yellow River Delta Efficient Ecological Economic Zone
}

\author{
Liping Zhao, Zhigang Yao
}

Department of life science, Binzhou University, Binzhou 256603

\begin{abstract}
Keywords: Evaluation system, Yellow River Delta efficient ecological economic zone, Modern agriculture
\end{abstract}

\begin{abstract}
In order to track, monitor, evaluate and accurately estimate the modern agricultural development level of efficient ecological economic zone in the Yellow River Delta, take the development level of modern agriculture comprehensive evaluation as the overall goal, and the agricultural infrastructure construction and material equipment level, quality of agricultural science and technology and agricultural laborers, agricultural organizational and informational level, the level of agricultural production and economic efficiency, agricultural society and ecological benefits as the grading index, the evaluation index system of modern agricultural Yellow River Delta Efficient Ecological Economic Zone was established; and takes six counties and one district of Binzhou City for the empirical analysis, proposed the suggestion of speeding up the modern agricultural development level of efficient ecological economic zone in the Yellow River Delta.
\end{abstract}

\section{Introduction}

March 17, 2008, Yellow River Delta Efficient Ecological Economic Zone Development Plan Shandong Provincial People's Government document Lu Zheng Fa [2008] No. 46. Issued by People's Government of Shandong Province, a clear status and importance of the development of the Yellow River in the province of Shandong Province focus on construction and development [1]. An important component of November 23, 2009 State Department letter to State ( 2009 ) No. 138 approved the issuance of "eco-efficient Yellow River Delta Economic Zone Development Plan", the rise of the Yellow River Delta efficient ecological economic zone construction and development of a national strategy, a national coordinated regional development strategy section. CPC Central Committee and State Council from 2009-2014, the continuous release of six central file, continuous focus on the "three rural" to promote the modernization of agriculture has become the theme and focus of agricultural development, local governments are exploring development paths suited to local modernization, also tried to develop a variety of agricultural modernization development goals. Yellow River Delta efficient ecological economic zone to develop a special high-efficiency ecological agriculture development plan (2010-2020), the development of modern agriculture traditional agriculture gradually intensive, standardization, modernization direction, promoting rural economic development and farmers to get rich pace, accelerating rural the historical process of building a moderately prosperous society and a new socialist countryside. However, the Yellow River Delta efficient ecological economic zone covers six city 19 counties, 292 townships jurisdiction, characteristics and advantages of regional agricultural differences, uneven development, different basic conditions of modern agriculture development in different regions, how to play the regional advantages, explore suitable road of modern agriculture development of regional sustainable development is an important issue restrict regional development of modern agriculture, and build evaluation system is an important method of modern agricultural development level to compare different areas. Established for the Yellow River Delta Index System of Agricultural Modernization efficient ecological economic zone, proposed goal of agricultural modernization, has a very important practical significance to the development of the Yellow River Delta efficient ecological economic zone.

In this study, by establishing the evaluation index system of efficient modern agricultural ecological economic zone in Yellow River Delta, with six counties and one district Binzhou city of 
empirical analysis as an evaluation unit level and stage of development of modern agriculture, the Yellow River Delta efficient ecological economic zone area according to local conditions, advantages, accelerating the sustainable development of modern agriculture to provide a reference.

\section{The establishment of evaluation index system}

\section{Establishment principle}

Modern agriculture is a complex dynamic system engineering, including economic, social, resources, ecological and other aspects, with a significant and multi-faceted nature of the multilevel nature [2]. According to construction principle, the evaluation of the content into a series of factors were evaluated, and then depending on the nature of the contact between them by selecting the appropriate rules to merge, to make an overall evaluation of its construction principles including the principle of comprehensiveness and independence, practicality and operational principles, regional and comparability principles, objective and forward-looking principle.

\section{Evaluation index selection}

In this study, expert consultation method and frequency statistics were adopted, in the light of domestic and foreign representative indicators setting, initially built a more complete evaluation index system of modern agriculture. Since this study for the Yellow River Delta efficient ecological economic zone, taking into account the availability of data, and ultimately build a comprehensive level of development of agricultural modernization as the overall index, comprising five-level indicators, 30 secondary indicators, specific indicators are in Table 1.

\section{Evaluation index weight determination}

In this study, based on economic, ecological and agricultural experts in the field of research on the use of the Analytic Hierarchy Process (AHP) to calculate the weight of each indicator values (Table 1).

\section{Index target level value determination}

To ensure that the party's 18 put forward in 2020 building a moderately prosperous society in the spirit and the Yellow River Delta efficient ecological economic zone to the 2020 agricultural development plan, determine the Yellow River Delta modern agriculture Evaluation Index System in accordance with the target year 2020; again According to the 2005-2012 average annual growth rate in August of each year evaluation (in Binzhou City, for example), and the corresponding analysis of various factors speed up the index value is calculated after eight years of positioning the target in 2020 (Table 1).

\section{The evaluation index system of modern agricultural Yellow River Delta Efficient Ecological Economic Zone}

Primary index and weight

A1 agricultural infrastructure construction and material equipment level indicator (0.2); A2 Agricultural Science and Agricultural laborers Quality Index (0.2); A3 agricultural organization and the level of information index (0.2); A4 agricultural production levels and economic indicators (0.2); A5 agriculture social and eco-efficiency indicators (0.2).

Secondary index and calculation method

A11 agriculture funds ratio (0.3): agriculture funds / financial capital * $100 \%$ of the total expenditure, the target $\geq 31$

A12 unit of cultivated agricultural machinery total power (0.3): Agricultural machinery total power / total cultivated area, the target $\geq 26$

A13 effective irrigation area proportion (0.2): effective irrigation area / * $100 \%$ of the total cultivated area, the target $\geq 82$ 
A14 per worker consumption (0.2): the total amount of agricultural electricity / total number of agricultural practitioners, target $\geq 1850$

A15 unit of cultivated fertilizer consumption (0.1): the total amount of agricultural chemical fertilizer / total cultivated area, the target $\geq 1.30$

A16 unit of arable land occupied various agricultural subsidy value (0.1): a variety of gross agricultural subsidies / total cultivated area, the target value $\geq 1300$

A27annual agricultural new technology promotion area rate $(0.2)$ : the promotion of new agricultural technology area / total area planted $* 100 \%$, the target $\geq 30$

A28 proportion of agricultural science and technology personnel (0.2): The total number of agricultural science and technology personnel / total number of agricultural labor force * $100 \%$ target $\geq 26$

A29 annual training rate for agricultural science and technology personnel: The total number of agricultural science and technology personnel training / total agricultural science and technology personnel * $100 \%$ target $\geq 100$

A210 rural adult high school or higher than (0.2): the total number of adult high school education / rural total adult $* 100 \%$ target $\geq 26$

A211 practical technical personnel in rural areas the proportion of (0.2): the total number of rural practical talents / total employees * $100 \%$ in rural areas, target $\geq 16$

A312 land scale operation specific gravity (0.2): Cultivated scale operation area / $* 100 \%$ of the total cultivated area, the target $\geq 15$

A313 Facility Agriculture ratio (0.2): the total area of agricultural facilities / total cultivated area * $100 \%$, the target $\geq 16$

A314 tractor area ratio (0.14): tractor with a total area / total area planted $* 100 \%$, the target $\geq 76$

A315 machine sowing area ratio (0.13): sowing machines with a total area / total area planted * $100 \%$, the target $\geq 76$

A316 machine income area ratio (0.13): The total area of machine income / total area planted * $100 \%$, the target $\geq 76$

A317 Farmers computer penetration rate (0.2): Rural households have a computer / rural total number of $* 100 \%$ target $\geq 56$

A418 agricultural output share of GDP (0.14): Agricultural GDP / GDP * 100\% of the total target value $\leq 6$

A419 gross value added of agriculture in GDP share (0.14): The total added value of the agricultural / total GDP * 100\%, the target $\leq 4$

A420 unit of cultivated grain yield (0.14): aggregate food production / total cultivated area, the target $\geq 13000$

A421 per capita consumption of meat (0.14): cattle, sheep, pigs, poultry output / total agricultural population, the target $\geq 220$

A422 input-output ratio (0.14): agricultural added value / intermediate consumption * $100 \%$ target $\geq 195$

Annual per capita net income of farmers A423 (0.15): total revenue from all sources, target $\geq 16000$

A424 Engel coefficient (0.15): total personal food expenditure / individual consumption * 100\% of total expenditure, the target $\leq 18$

A525 rural highway rate (0.14): Rural traffic village / total number of rural * $100 \%$ target $\geq 100$

A526 methane penetration rate (0.14): the number of households using biogas / $* 100 \%$ of the total rural households, the target $\geq 14$

A527 urbanization rate (0.18): the number of non-agricultural hukou / total population * $100 \%$ target $\geq 55$

A528 forest coverage (0.18): forest area / total land area * 100\% target $\geq 45$

A529 film coverage (0.18): mulching area / total area planted $* 100 \%$, the target $\geq 40$ 
A530 Hanlaobaoshou ratio (0.18): Hanlaobaoshou area / total area planted $* 100 \%$, the target $\geqslant$ 56

\section{Modern agricultural development evaluation of Yellow River Delta Efficient Ecological Economic Zone- take six counties and one district of Binzhou City as the example}

\section{Data resources}

Research using data mainly from the "Statistical Yearbook of Binzhou City," 2010, 2011, 2012 [3-5], and "Shandong Rural Statistical Yearbook," 2010, 2011, 2012 [6-8], part of the data reference to the county Farm Bureau statistics.

\section{The modern agricultural development phases classification}

Because of theoretical and empirical studies have not appeared on the stage of development of modern agriculture measure division, drawing on the basis of this study agricultural modernization research methods on the evaluation criteria to the FAO report on the status of research and eastern provinces of China for Agriculture reference, the stage of development of modern agriculture (evaluation value range) as follows: initial implementation phase ( $<50 \mathrm{~min})$, the initial implementation phase (50-70 points), the basic realization phase (70-90 minutes) and full implementation phase (> 90 minutes) four stages [9].

\section{Measurement and Analysis for the Evaluation of Modern Agricultural Development}

In this study, a comprehensive assessment method, the six counties Binzhou City, a district as an evaluation unit, evaluated its level of agricultural development in the present situation, the evaluation results indicate that Binzhou counties north coast, south of a county located in the north too Yishan middle three counties (districts) along the Yellow distribution, geology and geomorphology, soil and water conditions, environmental resources, are quite different. In modern agriculture to promote the process of development, there are also imbalances. After evaluation, the development of modern agriculture in 2012, has five counties and one district towards modern agriculture initial stage, a county into modern agriculture basic implementation phase.

Zouping County in southern piedmont alluvial plains, due to soil texture is superior, good conditions for agricultural production, to achieve a high degree of evaluation, the evaluation score reached 71.20 points, into a modern agricultural basic implementation phase, to become a leader; agriculture integrated Production levels and economic indicators to achieve the degree has reached $77.37 \%$, which is also higher than farmers' annual net income of ten thousand yuan level of 11,692.77 yuan. However, the realization of the social and ecological benefits of agriculture index was only 60.93 percent, ranked second to last six counties and one district, highlighting the rapid economic development of agriculture, ecological environment for the development lags behind the conflict, which should be the county and agricultural management attention, establish mechanisms for sustainable agricultural development, promote the development of eco-friendly modern agriculture; and to further emancipate the mind, seek progress, reform and innovation, increase industry nurturing agriculture and cities support for agriculture, accelerate agricultural modernization, it is necessary to strive for the municipal development of modern agriculture demonstration counties, but also striving demonstration counties in the Yellow River region.

Located in the north of the Yellow River, neither backing nor the sea, Yangxin County and Huimin County, evaluation scores were ranked last in the six counties and one district of the first and second place. Yangxin County, only scored 55.580 points, more than the bottom 20 percent Zouping leader, Huimin scored 59.29 points, more than 16 percentage points lower Zouping County were just entered the initial stage of development of modern agriculture. Yangxin County at 5-level evaluation system, in addition to achieve the degree of agricultural infrastructure and material equipment level index reached $63.64 \%$, the remaining four-level evaluation indicators are ranked No. 5. Both backward counties, in the future it is necessary to face up to poor agricultural production conditions, lack of 
environmental resources, the actual, but also to emancipate the mind, reform and innovation, unswervingly adhere to the agricultural infrastructure, increase agricultural investment, accelerate the development of modern agriculture.

Boxing County appraisal came in second and third of the coast of the city, respectively, scoring 66.46 points and 64.02 points, has entered a rapid development of modern agriculture and the initial stage of development, should make full use of the counties (districts) of favorable development of modern agriculture conditions, face unfavorable factors, depth of rural reform, accelerate the modernization of agriculture.

Two counties in the northern coast of Wudi County and Zhanhua County, modern agricultural development at the middle level, possession of a large amount of arable land per capita, much reserve land resources, but also the support of blue ocean economy, the county government and the agricultural administration, should face up to potential agricultural modernization, thoroughly implement the spirit of the Central Document No. 2014, comprehensively promote agricultural modernization.

The evaluation results of modern agricultural development, forestry, animal husbandry and after the city of land and water management experts to review, agreed that the six-county area in line with City actual development of modern agriculture, scientific evaluation system, system, concise, easy to operate, not only can this indicator system and the corresponding evaluation model in the Yellow River 19 counties (cities, districts) of modern agricultural development process can also be extended to the province's counties (cities, districts) in order to accelerate the overall development process of Shandong Agricultural modernization.

\section{Suggestion of speeding up the modern agricultural development level of efficient ecological economic zone in the Yellow River Delta}

Efficient ecological economic zone in the Yellow River Delta, across 19 counties in six urban areas (cities and districts) in Shandong Province, admin 292 towns, there are fewer people and large area, and the economic development between regions is very uneven. In agriculture modernization development steps, it should start from developed economical areas, such as Guangrao County of Dongying, Zouping County and Boxing County of Binzhou, Weifang County of Shouguang, etc., progressively advancing towards the northern coast. To speed up the modern agricultural development process in the efficient ecological economic zone of Yellow River Delta, it must take a variety of measures, such as strengthening agricultural infrastructure construction, expand the scale of land management, rely on scientific and technological progress and improving the quality of farmers, realize the industrialization of agriculture, and accelerate the pace of urbanization. In the agricultural modernization process, we must pay attention to the protection of ecological environment and realize sustainable development of agriculture.

\section{Acknowledgments}

This paper is the soft science research projects of Binzhou City, the name of the project is Modern Agriculture Evaluation Index System Establishment and Mmpirical Research of Yellow River Delta Efficient Ecological Economic Zone-take Binzhou City as the example, the project No.2014RKX15.

\section{References}

[1] Yellow River Delta Efficient Ecological Economic Zone Development Plan, Shandong Provincial People's Government document, Lu Zheng Fa [2008] No. 46.

[2] Li Baoyu, Li Gang, Gao Chunyu. Bohai modern agriculture index Evaluation System establishment and Development evaluation. Chinese Agricultural Science Bulletin, 2012,11: 133-139. 
[3] Binzhou Bureau of Statistics Yearbook (2011). Shandong: Bureau of Shandong Province Printing Center 2011.

[4] Binzhou Bureau of Statistics Yearbook (2012). Shandong: Bureau of Shandong Province Printing Center 2012.

[5] Binzhou Bureau of Statistics Yearbook (2013). Shandong: Bureau of Shandong Province Printing 2013.

[6] The Statistical Bureau of Shandong Province, Shandong Rural Statistical Yearbook (2011). Shandong: Shandong province bureau of statistics, 2011.

[7] The Statistical Bureau of Shandong Province, Shandong Rural Statistical Yearbook (2012). Shandong: Shandong province bureau of statistics, 2012.

[8] The Statistical Bureau of Shandong Province, Shandong Rural Statistical Yearbook (2013). Shandong: Shandong province bureau of statistics, 2013.

[9]Xing Ling, Jiang Heping. The establishment and calculation of Agricultural Modernization development evaluation Index System, Agricultural Modernization Research, 2010,06: 646-650. 